\title{
OFICINAS E LETRAMENTOS: METODOLOGIA PARA PROTOTIPAGEM DE JOGO DIGITAL DE MÍDIA-EDUCAÇÃO
}

\author{
Ana Cristina Nunes Gomes Muller ${ }^{1}$ \\ Dulce Márcia Cruz²
}

\section{Resumo}

Este artigo apresenta resultados de uma pesquisa sobre ampliação de letramentos no processo de produção do Game Comenius, um jogo digital de formação docente para as mídias. O jogo vem sendo criado na Universidade Federal de Santa Catarina tendo em vista as carências na utilização das mídias na prática docente de modo geral. Durante a produção do jogo, são ofertadas oficinas de prototipagem para investigar tanto a aprendizagem do uso das mídias como desenvolver um olhar de game designer pelos participantes. A produção dos dados é feita pela observação do jogar como jogador, professor e designer, e pela análise dos formulários on-line preenchidos pelos cursistas sobre a experiência. Como resultado, percebe-se uma ampliação dos letramentos midiáticos dos participantes tanto nas suas percepções sobre o planejar e jogar a aula como sobre o papel como game designers. Palavras-chave: Jogo digital. Formação docente. Mídias. Letramentos Digitais. Game Design.

\section{WORKSHOPS AND MULTILITERACIES: METHODOLOGY FOR PROTOTYPING}

\section{A MEDIA-EDUCATION GAME}

\begin{abstract}
This article presents results from a research on the expansion of literacies in the production process of Game Comenius, a digital game of teacher training for the media. The game has been created at the Federal University of Santa Catarina in view of the lack of use of the media in teaching practice in general. During the production of the game, prototyping workshops are offered to investigate both learning to use the media and developing a game designer look at the participants. The production of the data is done by observing play as a player, teacher and designer, and by analyzing the online forms completed by the learners about the experience. As a result, we can see an increase in the participants' media literacies, both in their perceptions of class planning and playing, and of their role of game designers.
\end{abstract}

Keywords: Digital game. Teacher training. Media. Digital literacies. Game Design.

1 Doutoranda em Educação, pelo Programa de Pós-Graduação em Educação da Universidade Federal de Santa Catarina. aninhagomesmuller@gmail.com

2 Professora Associada da Universidade Federal de Santa Catarina. dulce.marcia@gmail.com 


\section{INTRODUÇÃO}

Revista do Programa de Pós-Graduação em Educação - UNESC

Já é consenso na literatura que um dos pré-requisitos fundamentais para o uso efetivo das mídias digitais na escola é a formação docente. No entanto, mesmo com todos os esforços governamentais ainda há uma grande carência de formação para professores sobre o uso desses recursos na prática pedagógica, especialmente com relação ao uso de jogos digitais. Esse cenário motivou a criação de um jogo digital educativo voltado para o uso das mídias, o Game Comenius, no Centro de Ciências da Educação, na Universidade Federal de Santa Catarina.

O Game Comenius tem como objetivo ampliar os letramentos digitais de professores e estudantes de licenciatura. Em sua dissertação, Müller (2017) relatou o processo de produção do game em sua fase inicial, especialmente a realização de oficinas de teste dos três primeiros protótipos do jogo. Com essa escolha metodológica, se buscou tanto levantar informações para melhorar o jogo como também investigar de forma exploratória como a reflexão em grupo sobre os protótipos podia ampliar os letramentos digitais dos participantes. Para isso, foi desenvolvido um formulário on-line de avaliação do jogo baseado na divisão da equipe em três áreas de desenvolvimento: design, pedagógico e programação. Neste artigo, será descrito como foi o processo de elaboração do formulário on-line de avaliação e uma síntese do resultado da oferta das três primeiras oficinas dos protótipos. O objetivo é descrever como uma equipe de estudantes, em sua maioria não jogadores, sem experiência com produção de jogos digitais, criou ferramentas de acompanhamento originais para responder a suas necessidades criativas, mesmo que fora dos padrões profissionais ou acadêmicos, para desenvolver um jogo digital educativo.

\section{INSTRUMENTOS DE AVALIAÇÃO E TESTES DO(S) PROTÓTIPO(S)}

Chandler (2012) e Schuytema (2008) afirmam que uma etapa fundamental do desenvolvimento de jogos é o teste. Esse procedimento é importante para que o funcionamento deste artefato cultural seja garantido, evitando bugs e falhas. Além da melhoria do protótipo, um dos objetivos da elaboração do instrumento de avaliação foi proporcionar aos participantes do teste a possibilidade de Criar Educação, Criciúma, v. 8, no1, jan/jul 2019.- PPGE - UNESC 

partir do conhecimento e da experiência do participante, este poderia estar desenvolvendo ou potencializando letramento(s) digital(is).

Inicialmente, a proposta metodológica pensada pela equipe antes de formular os instrumentos de avaliação e testes foi desenvolver a avaliação por meio da heurística como uma possibilidade que poderia ser trabalhada na avaliação de protótipos. De acordo com Vieira e Amate (2012), a tabela heurística se constrói como o resultado da construção e experimentação de diversos autores para um resultado final. Para chegar a ela no caso específico, seria necessário elencar os autores relevantes da área e analisar de que forma conceituam os elementos principais que compõem os jogos digitais, tais como: narrativa, mecânica, gameplay, usabilidade, etc, por exemplo. Nesse processo, a partir das definições encontradas, uma alternativa seria analisar se os elementos do jogo a ser testado estavam de acordo com os itens fundamentais elencados por estes autores levantados na literatura. No entanto, no primeiro protótipo, as ideias precisavam ainda ser melhor desenvolvidas, o que gerou um retorno de informação muito abrangente sobre o jogo, impossibilitando uma avaliação com essas características heurísticas no início dos testes, que eram mais complexas e detalhadas para o ainda incipiente resultado inicial.

Diante disso, a equipe considerou desenvolver os formulários de avaliação e de testes com questionamentos menos específicos e mais gerais referentes a cada área de conhecimento: design, pedagógico e programação. Essa divisão dos formulários ocorreu por conta do próprio trabalho desenvolvido pela equipe, com o objetivo de facilitar um feedback específico para as necessidades de melhoria de cada área. Os itens foram retirados da própria prática e dos elementos da produção, não havendo um embasamento teórico para essa estruturação. O intuito era analisar se haveria um entendimento mínimo da proposta do jogo pelos participantes da oficina e também obter um feedback para o melhoramento dos próximos protótipos. Esse modo de operar estava baseado na inexperiência da equipe, tanto teórica como empírica, que precisava de retorno de um trabalho desenvolvido pela primeira vez na referida área de conhecimento. No entanto, isso não impede que em futuros protótipos na continuidade do projeto não se possa reformar os instrumentos de 

do game design.

\section{METODOLOGIA DE CONSTRUÇÃO PARA A AVALIAÇÃO E TESTES DO(S) PROTÓTIPO(S)}

Para a elaboração das perguntas da área de design, a equipe listou que feedback gostariam de receber para poderem melhorar nos próximos protótipos, encaminhando os questionamentos para ser validado pelo grupo antes de ser utilizado na oficina. No primeiro protótipo, ainda faltavam descrições do que o jogador precisaria fazer, botões mais explicativos, etc. Mesmo assim, nas perguntas referentes ao design, os bolsistas buscaram mapear a opinião dos jogadores sobre os elementos estéticos e funcionais, indagando sobre o que já era possível ser jogado no protótipo como o visual, a interface, as cores, os cenários, as figuras, os botões e os personagens.

Da mesma maneira foram listadas as questões de avaliação da programação, que buscavam verificar ao mesmo a interface tecnológica, a mecânica e a jogabilidade de uma maneira ainda bastante rústica. As perguntas nasceram da mesma forma que ocorreu com a equipe de design: o programador da equipe nos relatou quais as perguntas seriam importantes para a programação, não sendo utilizado nenhum autor para embasar as perguntas e sim o feedback do que ele gostaria de receber. O programador encaminhou os questionamentos e a equipe validou antes de utilizarmos na oficina. Questionamentos sobre falhas e bugs no jogo eram de extrema importância serem apontados para posterior correção. Assim, analisar se o jogo estava difícil de jogar e o desempenho do programa do computador foram itens fundamentais para que pudesse ocorrer a melhoria contínua do artefato cultural.

A equipe pedagógica também avaliou quais questionamentos eram importantes para a área educacional do jogo, pois se tratava de um jogo de educação para as mídias. Por isso, pensou suas questões de modo geral, voltadas para a compreensão do jogo, regras, objetivos, desafios, satisfação e pontos positivos e negativos, buscando também sugestões de melhoria. Compreender 0 
objetivo do jogo e qual a sua finalidade eram itens de extrema importância para serem levantados para que a equipe pudesse fazer as correções necessárias.

Antes mesmo desse instrumento de análise do jogo, o grupo de pesquisa Edumídia/CNPq, ao qual o Game Comenius está associado, criou um perfil midiático que foi aplicado online com abrangência nacional, em 2014, para levantar as características dos estudantes de licenciatura presencial e a distância (CRUZ, 2015). Com o início dos testes do jogo, o formulário passou também a ser aplicado nas oficinas com o intuito de mapear o perfil midiático dos participantes que iriam testar os protótipos. Os resultados do perfil midiático aplicado não serão analisados neste artigo.

Após as oficinas de formação e testes dos protótipos, a equipe poderia analisar as respostas e discutir o que poderia ser implementado ou não. Além disso, a proposta dos formulários foi servir de base para avaliar quais as contribuições dos feedbacks para a equipe, se o jogo alcançou seu objetivo a partir das respostas e quais os letramentos digitais desenvolvidos e/ou potencializados pelos participantes ao jogarem e avaliarem o jogo. A seguir, serão descritos os momentos das oficinas de formação dos três primeiros protótipos do Game Comenius.

\subsection{DESCRIÇÃO DAS OFICINAS DE FORMAÇÃO}

O público-alvo do Game Comenius são professores e estudantes de licenciatura que vão atuar ou já atuam na educação. A seguir serão descritas as três primeiras oficinas de formação, ocorridas entre 2015 e 2016, em que foram avaliados os respectivos protótipos pelos participantes.

A partir das discussões, contribuições e preenchimento dos formulários online pelos participantes, consideramos, também, que esses encontros poderiam ser considerados formação docente para o uso das mídias, que proporcionaram o desenvolvimento e/ou potencialização de letramentos digitais. No que tange à etapa de testes, Chandler (2012) considera esta uma fase crítica, pois é quando o jogo é analisado com o intuito de verificar o seu funcionamento e se não há bugs. Schuytema (2008) afirma que é no processo de produção que o setor de testes começa a avaliação de cada versão do jogo, ou seja, de cada protótipo. E as 
avaliações formativas, para Preece, Rogers e Sharp (2005), são efetuadas com o intuito de analisar se o produto responde às necessidades do público-alvo.

Nesta pesquisa, a análise de conteúdo foi realizada a partir dos questionários on-line respondidos pelos participantes nas oficinas de formação e testes dos protótipos. Para Martins (2008) a análise de conteúdo pode ser resumida em três etapas, conforme descritas a seguir:

a) Pré-análise: organização e coleta de dados que são analisados.

b) Descrição analítica: análise aprofundada dos dados, que se orienta por hipóteses a partir do referencial teórico utilizado na pesquisa. Os dados são organizados a partir de algum critério, tornando-se categorias.

c) Interpretação inferencial: a partir das categorias utilizadas, com base no referencial teórico, os conteúdos são analisados a partir do seu propósito de análise.

No que se refere à pré-análise, foram coletados os dados dos questionários de avaliação do jogo digital Comenius. No que se refere à descrição analítica, as categorias foram mantidas no mesmo formato em que estavam disponíveis nos formulários on-line de avaliação (design, programação e pedagógico). Por fim, no que se refere à interpretação inferencial, o objetivo era analisar a importância dos testes do processo de avaliação dos protótipos e o seu progresso no próprio desenvolvimento das oficinas a partir do feedback dos participantes.

\section{PRIMEIRO PROTÓTIPO}

No dia 23 de outubro que 2015, das $8 \mathrm{~h}$ às $12 \mathrm{~h}$, ofertamos a primeira oficina do jogo digital Comenius na SEPEX, Semana de Ensino, Pesquisa e Extensão da UFSC, com o objetivo de obter a primeira avaliação dos 10 participantes inscritos. Essa oficina foi um minicurso aberto, pois neste evento os alunos da UFSC podem se inscrever antecipadamente nas oficinas que desejam participar, portanto os participantes não foram escolhidos, mas sim inscritos pelo próprio interesse na temática.

O resultado dos formulários mostrou, como era esperado, que os participantes consideraram o jogo ainda em fase inicial, pois faltavam orientações, botões mais explicativos, entre outros. No que se refere ao design, os participantes 
afirmaram que o objetivos e instruções do jogo não estavam claros. A maioria não compreendeu o significado dos ícones do jogo, como também não gostaram do desenho dos botões. No que se refere à programação, os participantes não compreenderam os controles do jogo. No que se refere ao pedagógico, a maioria não compreendeu as regras do jogo e não se sentiram satisfeitos ao jogar. Sobre as propostas de mudanças no ciclo do jogo, foi sugerido: deixar os objetivos e funcionalidades do jogo mais claros, desenvolver tutoriais que explicassem a dinâmica do jogo e um personagem guia que instruísse o jogador na primeira missão.

A partir desses dados a equipe continuou o processo de produção que geraria o segundo protótipo, dessa vez com mais elementos no jogo.

\section{SEGUNDO PROTÓTIPO}

No dia 03 de março de 2016, das $13 \mathrm{~h} 30 \mathrm{~min}$ às $17 \mathrm{~h}$, foi realizada a segunda oficina para a avaliação do segundo protótipo. Os participantes foram 10 estudantes do curso de Pedagogia, na disciplina Comunicação e Educação. Diferente dos participantes da oficina da SEPEX, para a segunda oficina os participantes foram escolhidos, principalmente por serem o perfil de jogadores do Game Comenius. Os formulários de avaliação foram os mesmos do primeiro protótipo.

Algumas dificuldades foram encontradas no segundo protótipo, tais como: os participantes não sabiam a regra básica do jogo (havia combinações pedagógicas que pontuavam mais); podiam escolher as opções de forma aleatória e a pontuação não relacionava com as melhores escolhas; algumas opções deveriam estar em espaços de aprendizagens, como: "ir a campo" quando a missão solicitada era "pesquisa"; as notas diminuíam com as missões seguintes e alguns computadores travavam e demoravam a carregar. No entanto, por mais que houvesse imprevistos que precisavam ser ajustados, notou-se uma melhora visível em relação ao primeiro protótipo. No que se refere ao design, todos os participantes compreenderam o significado dos botões, que no primeiro protótipo era uma dificuldade. No que se refere à programação, o sistema estava lento para a metade dos participantes e foram também encontrados muitos bugs no sistema. No que se refere ao pedagógico, houve um entendimento melhor sobre a proposta do jogo. No entanto, 
foram sugeridas algumas melhorias, principalmente nas combinações no planejamento da aula, tais como: mais opções de combinações, deixar mais clara a missão e ter mais opções para o planejamento na agenda.

\section{TERCEIRO PROTÓTIPO}

Nos dias 19 e 20 de maio de 2016, das $13 \mathrm{~h} 30$ às 17h, foi realizada a terceira oficina para a avaliação do terceiro protótipo. Os 30 participantes, assim como da segunda oficina, eram os alunos do curso de Pedagogia, na disciplina Comunicação e Educação. A oficina ocorreu em dois dias por se tratar de duas turmas da mesma disciplina, e como se tratava do mesmo protótipo, a narrativa desta oficina será feita como se houvesse acontecido apenas um único encontro. Os formulários de avaliação foram os mesmos do primeiro protótipo.

Em relação às oficinas anteriores, foi perceptível que a terceira versão do protótipo estava mais jogável por conta das implementações sugeridas nas oficinas anteriores, embora ainda fossem necessários alguns ajustes e complementações. $O$ bug ocorrido no primeiro dia da oficina impactou bastante, visto que, no dia seguinte, com o problema solucionado, os participantes jogaram sem mais questionamentos. A equipe precisava trabalhar, de acordo com as sugestões, no que se refere à teoria que embasava as missões para que os jogadores pudessem comparar as escolhas certas e erradas e, assim, analisar quais recursos eram mais adequados ou não de acordo com a metodologia escolhida no planejamento.

Sobre a análise do jogo nas três áreas de conhecimento analisadas (design, programação e pedagógico) podemos afirmar que, no que se refere ao design, $57 \%$ dos participantes acharam que havia uma coesão visual entre as partes do jogo e $82 \%$ entenderam o significado das figuras do jogo. A estética teve uma grande evolução no terceiro protótipo já que os participantes compreenderam os elementos visuais sem dificuldades. Uma sugestão dos participantes era que houvesse mais interação dos personagens com os espaços do jogo, mostrados no próprio mapa do jogo.

No que se refere à programação, $57 \%$ dos participantes afirmaram que compreenderam os controles do jogo, $67 \%$ consideraram o desempenho do jogo 
rápido e $71 \%$ encontraram bugs no jogo, o que se justifica pelo problema relatado no primeiro dia em que ao selecionar qualquer mídia sempre aparecia o globo terrestre.

No que se refere ao pedagógico, os participantes compreenderam que o objetivo do jogo era planejar uma aula de acordo com a metodologia mais adequada e que os recursos deveriam ser coerentes com o método. A proposta era que se pensasse em aulas mais midiáticas e isso deveria ser analisado no planejamento. Por fim, 64\% dos participantes afirmaram que compreenderam as regras do jogo, cujo objetivo era planejar uma aula de acordo com a missão, pensando nas melhores estratégias e mídias que se adequassem ao tipo de aula.

\section{CONCLUSÃO}

A construção coletiva dos formulários on-line para avaliação e testes dos protótipos foi fundamental para que a equipe pudesse refletir seu trabalho e aplicar as melhorias sugeridas a cada versão disponibilizada nas oficinas. A evolução do Game Comenius sofreu uma importante influência das avaliações realizadas nas oficinas bem como das conversas informais que ocorreram nesses espaços que tiveram a função tanto de formação docente quanto de testes dos protótipos.

Como conclusão, pode-se dizer que a escolha metodológica de realizar os testes em forma de oficina de formação para as mídias acoplada à aplicação dos formulários enriqueceu o processo criativo e apoiou o letramento de todos os envolvidos, pois os participantes pensaram junto com a equipe e de certa maneira participaram da construção coletiva do artefato cultural. A evolução dos protótipos foi acompanhada de resultados positivos da avaliação e também de uma maior compreensão da mecânica do jogo. Por essa razão, tanto o formulário como o formato da oficina, mesmo que não embasados numa literatura de game design, foram úteis para testar e divulgar o Game Comenius junto ao seu público-alvo e ajudaram a alcançar seu objetivo de propor ao jogador planejar, executar e avaliar uma aula utilizando as mídias digitais.

\section{AGRADECIMENTOS}


Agradecemos ao Conselho Nacional de Desenvolvimento Científico e Tecnológico (CNPq) pelo apoio dos editais Chamada Universal 14/2013 e Chamada MCTI/CNPQ/MEC/CAPES № 22/2014 Ciências Humanas, Sociais e Sociais Aplicadas e pela bolsa-produtividade, os quais deram suporte à realização desta pesquisa.

\section{REFERÊNCIAS}

CHANDLER, Heatler Maxwell. Manual de produção de jogos digitais. Porto Alegre: Bookman, 2012.

CRUZ, D. M.. Comenius: uma proposta de pesquisa, produção de jogos eletrônicos e formação docente para as mídias. 2016. (Relatório de pesquisa).

MARTINS, Gilberto de Andrade. Estudo de caso: uma estratégia de pesquisa. São Paulo: Atlas, 2008.

MÜLLER, Ana Cristina Nunes Gomes. Game Comenius: produção de um jogo digital de educação para as mídias. 2017. 175 f. Dissertação (Mestrado em Educação) - Programa de Pós-graduação em Educação da Universidade Federal de Santa Catarina, Florianópolis, 2017.

PREECE, Jennifer; ROGERS, Yvonne; SHARP, Helen. Design de interação: além da interação homem-computador. Porto Alegre: Bookman, 2005.

SCHUYTEMA, Paul. Design de games: uma abordagem prática. São Paulo: Cengage Learning, 2008.

VIEIRA, A. S; AMATE, F.C. Análise de características heurísticas em interface de jogos computadorizados. In: CONCISTEC 2012, 2012, Bragança Paulista. 3o Congresso Científico da Semana Nacional de Ciência e Tecnologia no IFSP. Bragança Paulista, 2012.

Recebido em dezembro 2018

Aprovado em março 2019 